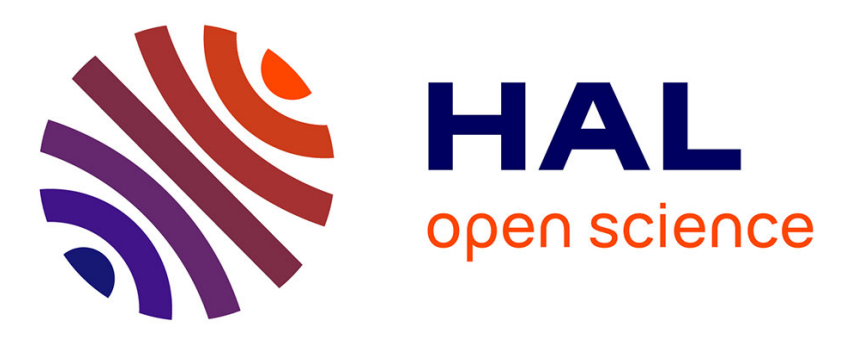

\title{
Continuous Intra Ocular Pressure Measurement Sensor for Glaucoma Diagnostic
}

Gaelle Bazin Lissorgues, Lionel Rousseau, Patrick Poulichet, Laurie Valbin, Serge Picaud, Laurent Chicaud, Serge Bernard, Philippe Bergonzo, Francois Dedieuleveult, Philippe Auvray

\section{To cite this version:}

Gaelle Bazin Lissorgues, Lionel Rousseau, Patrick Poulichet, Laurie Valbin, Serge Picaud, et al.. Continuous Intra Ocular Pressure Measurement Sensor for Glaucoma Diagnostic. 6th World Congress of Biomechanics (WCB), Aug 2010, Singapore, Singapore. pp.1282-1285, 10.1007/978-3-642-145155_325. lirmm-00808458

\section{HAL Id: lirmm-00808458 https://hal-lirmm.ccsd.cnrs.fr/lirmm-00808458}

Submitted on 13 Jan 2020

HAL is a multi-disciplinary open access archive for the deposit and dissemination of scientific research documents, whether they are published or not. The documents may come from teaching and research institutions in France or abroad, or from public or private research centers.
L'archive ouverte pluridisciplinaire HAL, est destinée au dépôt et à la diffusion de documents scientifiques de niveau recherche, publiés ou non, émanant des établissements d'enseignement et de recherche français ou étrangers, des laboratoires publics ou privés. 


\title{
Continuous Intra Ocular Pressure Measurement Sensor for Glaucoma Diagnostic
}

\author{
Gaëlle Lissorgues ${ }^{1}$, Lionel Rousseau ${ }^{1}$, Patrick Poulichet ${ }^{1}$, Laurie Valbin ${ }^{1}$, Serge Picaud ${ }^{2}$, Laurent Chicaud ${ }^{2}$, Serge Bernard ${ }^{4}$, \\ Philippe Bergonzo ${ }^{3}$, Francois Dedieuleveult ${ }^{3}$, and Philippe Auvray ${ }^{5}$ \\ ${ }^{1}$ ESYCOM, ESIEE, Noisy le Grand, France \\ ${ }^{2}$ Institut de la Vision, INSERM, Paris, France \\ ${ }^{3}$ LIST, CEA, Saclay, France \\ ${ }^{4}$ LIRMM, Université II Montpellier, Montpellier, France \\ ${ }^{5}$ OPHTIMALIA, SME, Colombelles, France
}

\begin{abstract}
Glaucoma is an ocular pathology usually associated with an increase in Intra Ocular Pressure (IOP). In this study, we are developing disposable eye lenses including a specific micro fabricated pressure sensor to measure IOP all day long. The information data will be wireless transferred via magnetic coupling to an external receiver. Our first work deals with the sensor design and fabrication. Simulation results based on classical electronic circuit tools will be presented and lead to several sensor solutions working at different RF frequencies. The fabrication process of the first sensors will also be described and an early IOP characterisation set-up will be presented to try to later quantify the sensor sensitivity, with IOP variations measured in the range 20 to $70 \mathrm{mmHg}$.
\end{abstract}

Keywords- Biomedical engineering systems, microfabricated sensors, IOP measurement, Glaucoma diagnostic.

\section{INTRODUCTION}

Glaucoma being an ocular pathology, which leads to the second cause of blindness in people over the age of 50, the aging of the world population will lead to further increasing the number of patients greatly visually impaired by this disease. In most cases, glaucoma is associated with an increase in Intra Ocular Pressure (IOP) [1]. Different hypotheses have been put forward to explain the degeneration of ganglion cells, which often occurs after an increase in intraocular pressure. One of these hypotheses is that the compression of the optic nerve and associated blood vessels could result in retinal ischemia with excitotoxicity of the retinal tissue and current treatments are essentially based on diminishing intraocular pressure [2].

In this study funded within the project ANR TecSan MATEO, we are developing disposable eye lenses including a specific pressure sensor to measure IOP all day long, and the instrumented lens will communicate by radio frequency to an electronic chip located on a glass branch. The daily information would thus be available for ophthalmologists to improve diagnostics. Indeed, ophthalmologists can only measure the intra-ocular pressure punctually, when the patient is visiting the ophthalmologist's practice, most often using the Goldmann applanation tonometer method. Moreover, the intraocular pressure can only be well controlled at the time of the visit due to proper medication but remains partly uncontrolled during the remaining part of the day. Depending on the advancement of glaucomatous damage to the optic nerve, closer monitoring seems to be necessary. Detailed knowledge of the behavior of IOP in patients with glaucoma is of paramount importance, as increased IOP and wide diurnal IOP variations are considered major risk factors for the progression of glaucoma [3, 4].

This work will offer a way to monitor continuously the IOP, on the typical basis of one measurement every 15 minutes, sufficient to monitor daytime variations, or every 5 minutes on diagnostic mode to try to associate the relationship with the physical environment of the patient (posture, activity, environment etc).

\section{General DeVICE Description}

\section{A. Operation Principle}

The final device will be a disposable lens containing a pressure or deformation sensor which transfers the information via magnetic coupling to the reusable receiver fixed on the glasses. Then data are stored in a portable device and transferred to a computer for further processing and analysis, see Fig. 1. Moreover this lens will be disposable to avoid any sterilization problems between patients or during long-term use. Therefore, our aim is also to limit electronic content on the lens to minimize its individual cost and complexity level.

The key element of this innovative measurement method is a soft contact lens with an embedded microfabricated sensor that allows the measurement of changes in cornea curvature correlated to IOP, as previously studied by $[5,6]$. 


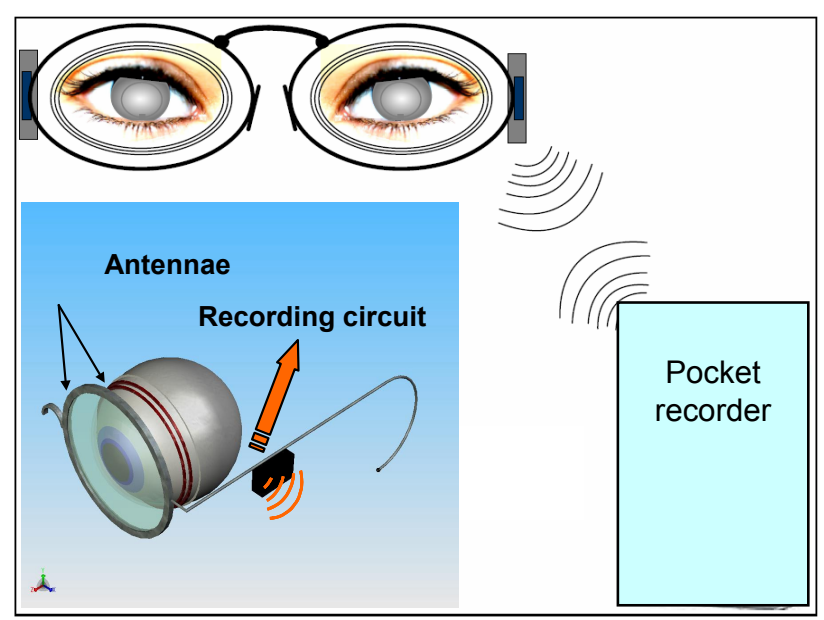

Fig. 1 Conceptual view of the system

Because of the short distance between the eyes and a pair of glasses, typically less than $3 \mathrm{~cm}$, the RFID protocol to measure the deformation of the lens can be used or any contact less communication protocol. As well as offering comfort to the patient, a wireless link protocol offers also the opportunity not to require any battery on the lens. The system will consist of an implanted sensor (corresponding to the RFID tag) and an external reader on the glasses, see Fig. 2. The system is therefore based on inductive coupling between the coils L1 and L2 respectively representing the reader and the embedded sensor.
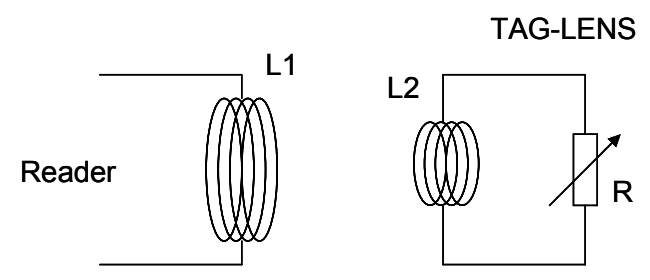

Fig. 2 Principle of the wireless communication (sensor in the lens and reader on glasses)

\section{B. Electrical Simulations}

The operation principle relies on resonant circuit modifications which can be simulated using classical electronic circuit tools applied on a transformer structure. The schematic of fig. 2 can be modified in Fig. 3 to extract the equivalent impedance $\mathrm{Z} 1$ in which appear 3 parameters: the coupling coefficient $\mathrm{k}$, the quality factor $\mathrm{Qs}$, and the resonance frequency $\omega \mathrm{s}=2 \pi \mathrm{fs}[7]$.

$$
\begin{gathered}
Z 1=j \cdot L_{r} \omega \cdot\left[1-k^{2} \frac{\left(j \frac{\omega}{\omega s}\right)^{2}}{1+j \cdot \frac{1}{Q s} \frac{\omega}{\omega s}+\left(j \frac{\omega}{\omega s}\right)^{2}}\right] \text { with } \\
k=\frac{M}{\sqrt{L r \cdot L s}} Q_{s}=\frac{1}{R s} \sqrt{\frac{L s}{C s}} \omega_{s}=\frac{1}{\sqrt{L s \cdot C s}} \\
\text { Reader }
\end{gathered}
$$

Fig. 3 Equivalent circuit of the sensor in the lens and reader on glasses based on magnetic coupling

The relative frequency variation is directly related to the LC component variations, as expressed below.

$$
\frac{\Delta f}{f}=-\frac{1}{2} \frac{\Delta L}{L}-\frac{1}{2} \frac{\Delta C}{C} \text {. Then any component variation }
$$
induced by a mechanical deformation at the cornea will be converted into a frequency shift, either detectable while measuring the impedance magnitude or phase, Fig. 4.

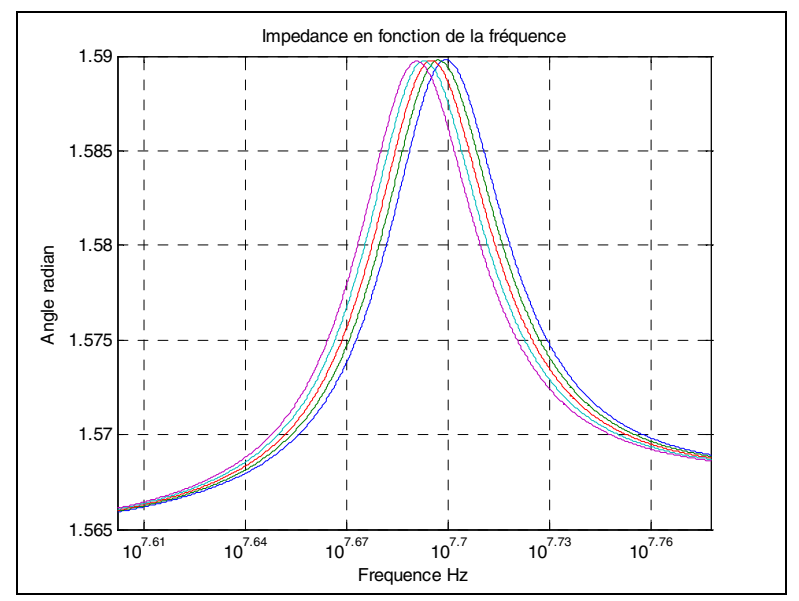

Fig. 4 Induced phase shift of $Z 1$ versus the frequency, for 1 to $5 \%$ inductance variations - example at $50 \mathrm{MHz}$

To optimize the global sensor operation, the coupling coefficient $k$ must be as high as possible, meaning that the 
distance between the instrumented lens and the glasses should be reduced. The quality factor must also be enhanced at the lens level, meaning high inductance values with low resistive loss and small capacitance values, as for example at $868 \mathrm{MHz}, \mathrm{L}=40 \mathrm{nH}, \mathrm{R}<1 \mathrm{Ohm}$, with $\mathrm{C}=0.8 \mathrm{pF}$. Based on this transformer structure, the wireless link can use RFID standards: at $125 \mathrm{kHz}$ with maximal range of $10 \mathrm{~cm}$ using a piezoelectric sensor, at $13.56 \mathrm{MHz} / 27 \mathrm{MHz}$ with maximal range of $1 \mathrm{~m}$ using a first kind of LC based sensor or at $868 \mathrm{MHz}$ with maximal range of $2 \mathrm{~m}$ using a second kind of LC based sensor.

\section{Device FAbrication}

To perform the monitoring IOP, we proposed to develop a disposable lens that follows the deformation of the cornea caused by the modification of IOP. We need a technology that offers the possibility to measure a small deformation of the cornea (typically about $3 \mu \mathrm{m}$ ) through a transparent and disposable lens. Traditional MEMS technology proposes several solutions for pressure or deformation sensing, either based on piezoresistive or piezoelectric gauges, or on capacitance variations. As previously explained, a derivative solution has been chosen based on inductance and capacitance variations using a resonating circuit. And the sensor will be coupled to an integrated antenna required for the magnetic coupling within a reduced surface corresponding of the iris diameter (typ. $1 \mathrm{~cm}$ ).

Concerning the fabrication, as it is required to adapt the technology onto an optically transparent soft material, i.e. based on a polymer lens, not to affect the vision of the patient, a low temperature process and low stress technology has been defined and tested, see Fig.5. Several prototypes are currently being fabricated, with examples shown on fig.6, and fig.7 for an embedded LC sensor.

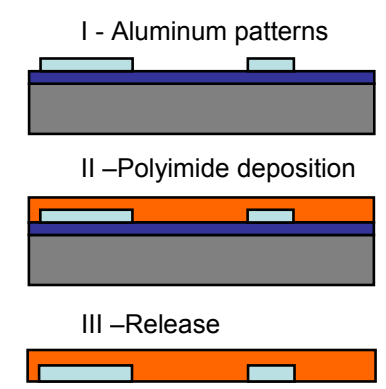

A)
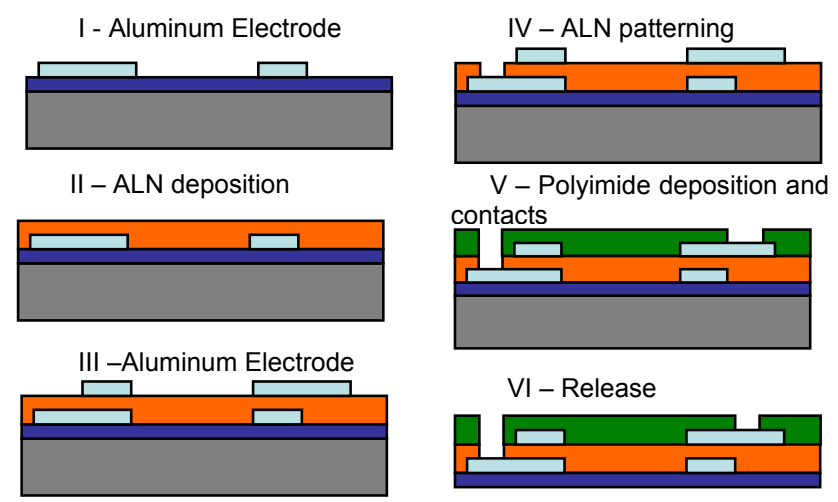

B)

Fig. 5 Fabrication process A) LC sensors B) piezoelectric sensors

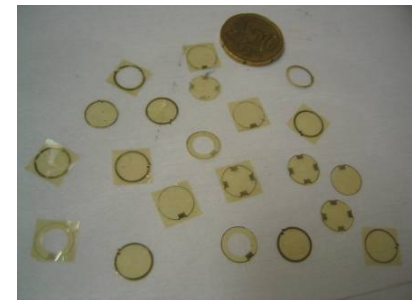

A)

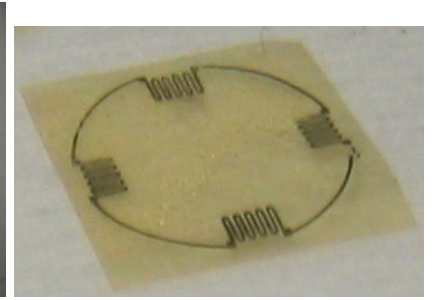

B)
Fig. 6 Example of fabricated sensors A) metal TiW/Au on polyimmide of $10 \mu \mathrm{m}$ thickness B) AlN based sensor on similar polyimide

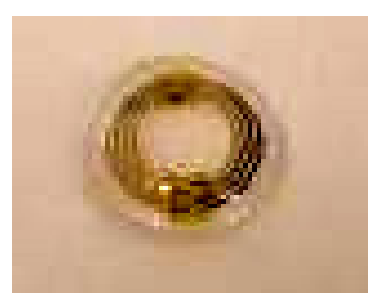

Fig. 7 Example of a fabricated LC sensor embedded into a soft lens

\section{IOP CHARACTERISATION SET-UP}

In parallel, early characterization of the IOP increase versus the eye deformation has been performed to try to quantify the sensor sensitivity, with IOP variations measured in the range 20 to $70 \mathrm{mmHg}$.

\section{A. Set-Up Description}

An experimental test bench has been set up to demonstrate the operation principle of the system using a proof of concept LC based prototype. Impedance measurements 
have been performed with an HP4195 Analyser, an inductive antenna representing the reader (on glasses) being connected to the analyzer and the embedded sensor being put on an isolated pig eye $2 \mathrm{~cm}$ under the reader.

In parallel, early characterization of the eye's deformation has been developed. The principle relies on micro injection of fluid (Ringer) inside the eye's inner chamber, with a volume step of $10 \mu \mathrm{L}$, correlated to IOP measurement performed using a Tonolab TV02 (accuracy of $\pm 2 \mathrm{mmHg}$ ).

\section{B. First Experimental Results}

The relation between the injected fluid and the measured IOP is shown on Fig.8. We will then use this simple principle to increase the intra ocular pressure in isolated pig eyes on which the sensor is electrically tested. We can observe on Fig.9 that the impedance magnitude and phase are slightly changing while the IOP is increased from 10 to $70 \mathrm{mmHg}$, demonstrating the feasibility of such a sensor.

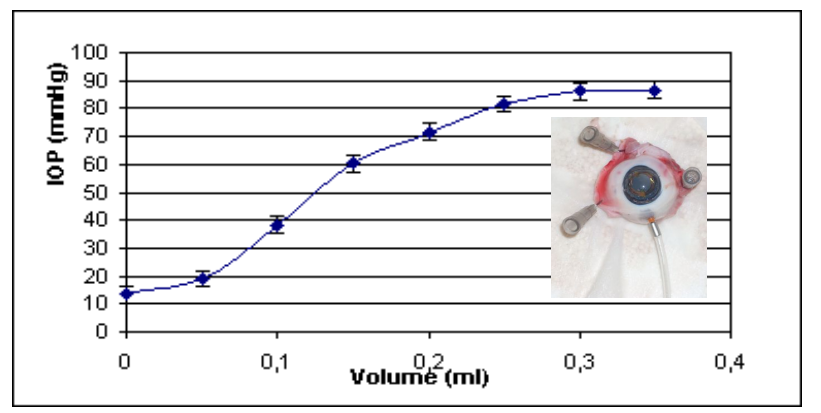

Fig. 8 Measured IOP vs. injected fluid volume
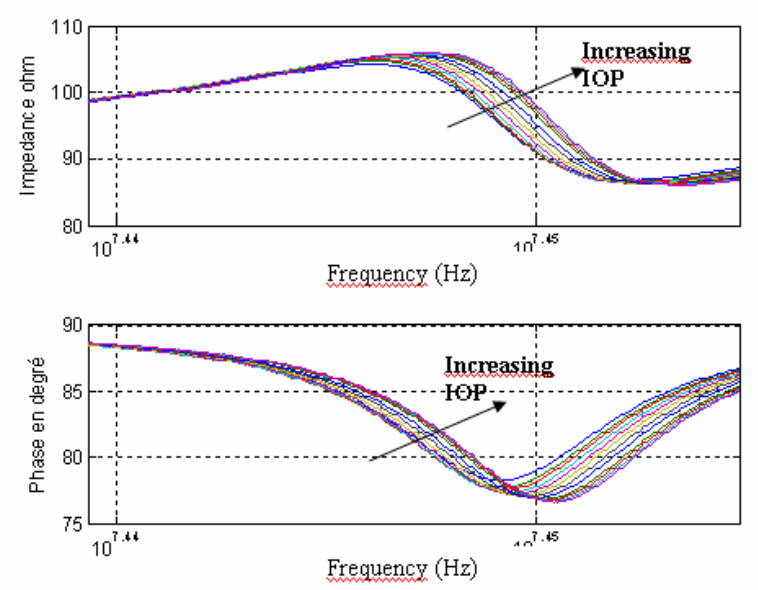

Fig. 9 Measured Impedance vs. frequency with IOP varying from 10 to $70 \mathrm{mmHg}$

\section{Conclusions}

We proposed a sensor embedded into a transparent lens to measure the intra ocular pressure. First proof of concept prototypes have been fabricated and tested to assess the operation principle of the system. Further work is focusing on several ways. First, one study concerns the optimization of the existing sensors, and the development of alternative piezoelectric sensors to compare the performances with LC based sensors. Second, the electronic and communication protocol is under development in parallel. And third, the experimental set-up is being improved.

\section{ACKNOWLEDGMent}

The authors want to acknowledge the French Research Agency (ANR) for its support during this project.

\section{REFERENCES}

1. Hattenhauer MG, Johnson DH, Ing HH, Herman DC, Hodge DO, Yawn BP, Butterfield LC, Gray DT. (1998) The probability of blindness from open-angle glaucoma. Ophthalmology. 105:2099-104.

2. Costa VP (2003) The effects of antiglaucoma and systemic medications on ocular blood flow. Prog Retin Eye Res. 22:769-805.

3. Asrani S, Zeimer R, Wilensky J, Gieser D, Vitale S, Lindenmuth K. Large diurnal fluctuations in intraocular pressure are an independent risk factor in patients with glaucoma. J Glaucoma. 2000;9: 134-142.

4. Hughes E, Spry P, Diamond J. 24-Hour monitoring of intraocular pressure in glaucoma management: a retrospective review. J Glaucoma. 2003;12:232-236.

5. Leonardi M (2003) Intraocular Pressure Recording System. Intern. Publication Number WO 03/001991 A1.Smith J, Jones M Jr, Houghton L et al. (1999) Future of health insurance. N Engl J Med 965:325-329.

6. First Steps toward Noninvasive Intraocular Pressure Monitoring with a Sensing Contact Lens, Matteo Leonardi, Peter Leuenberger, Daniel Bertrand, Arnaud Bertsch, and Philippe Renaud, IOVS, September 2004, Vol. 45, No. 9.

7. Microfabricated Implantable Parylene-Based Wireless Passive Intraocular Pressure Sensors, Po-Jui and All, Journal of Microrelectromecanical Systems, Vol. 17, $\mathrm{N}^{\circ} 6$, December 2008.

\author{
Author: Lissorgues Gaëlle \\ Institute: ESYCOM - ESIEE \\ Street: Cité Descartes BP 99, 2 Bd Blaise Pascal \\ City: $\quad 93162$ Noisy le Grand \\ Country: France \\ Email: g.lissorgues@esiee.fr
}

